O.O. Palchykov

\title{
DETERMINATION OF THE EFFECTIVE PERMITTIVITY OF A HETEROGENEOUS MATERIAL
}

Purpose. To develop a two-dimensional numerical-field model for determining the effective permittivity of a multicomponent material represented by a system of homogeneous volumes with known physical characteristics. Methodology. The model is based on the solution by the finite element method of an electrostatic problem with the subsequent determination of the energy contained in the volume under consideration. Than we have compared this result with the energy of a flat capacitor with a rectangular cross-section of the plates and determined the effective permittivity of test material. We also have used Rayleigh, Odelevsky and Lichtenecker models and the model with a perpendicular arrangement of layers relative to the main electric flux. Results. Based on the developed field model, the effective permittivities for dry, wet and transformer oil-soaked insulating papers of various grades, including taking into account ash, are determined. We have proved that a macroscopically homogeneous multicomponent material is well approximated by uniformly spaced cylindrical volumes with a substance of different nature in a matrix of another substance. We have showed a significant error of the layer model and the Rayleigh model relative to the proposed model. We have showed the equivalence of models with the location of inclusions in the nodes of a rectangular and parallelogram mesh. Originality. For the first time we have proposed wet paper models with an asymmetric arrangement of a cylindrical volume of water with a circular and segment cross-section in a cylindrical pore. For the first time we have proposed models of insulating paper with evenly spaced cylindrical inclusions of different volumes. Practical value. The proposed model allows to calculate the effective permittivity of an inhomogeneous material with a given accuracy without restricting the shape of the components. Based on the proposed field model, it is possible to determine the Lichtenecker index, which allows to calculate the effective permittivity for any ratio of the volumes of the components of a heterogeneous material. References 10, tables 3, figures 4.

Key words: effective permittivity, electrostatic field, energy, finite element method, cylindrical volumes.

Обгрунтовано застосування методу, заснованого на чисельному розрахунку електростатичного поля для визначення ефективної діелектричної проникності гетерогенного матеріалу, який замінясться системою однорідних об'ємів 3 відомими фізичними характеристиками. Для сухого, вологого і просоченого трансформаторним маслом ізоляційних паперів різних марок визначені діелектричні проникності. Результати розрахунку за запропонованими моделями зіставлялися з результатами, отриманими на основі шаруватої моделі, моделей Релея і Оделевського. Запропоновані апроксимаційні залежності на основі узагальненого виразу Ліхтенеккера для визначення діелектричної проникності ізоляційних паперів. Бібл. 10, табл. 3 , рис. 4.

Ключові слова: ефективна діелектрична проникність, електростатичне поле, енергія, метод скінченних елементів, циліндричні об'єми.

Обосновано применение метода, основанного на численном расчете электростатического поля для определения эффективной диэлектрической проницаемости гетерогенного материала, который представляется системой однородных объемов с известными физическими характеристиками. Для сухой, влажной и пропитанной трансформаторным маслом изоляционных бумаг различных марок определены диэлектрические проницаемости. Результаты расчета по предложенным моделям сопоставлялись с результатами, полученными на основе слоистой модели, моделей Рэлея и Оделевского. Предложсены аппроксимационные зависимости на основе обобщенного выражения Лихтенеккера для определения диэлектрической проницаемости изоляционных бумаг. Библ. 10, табл. 3, рис. 4 .

Ключевые слова: эффективная диэлектрическая проницаемость, электростатическое поле, энергия, метод конечных элементов, цилиндрические объемы.

Introduction. In the manufacture of electrical machines, apparatus and power capacitors, various insulating materials are used, such as multicomponent (varnished fabrics and varnished paper, electrical insulating tapes, laminated plastics, electrical ceramics), and almost uniform ones, such as mica and cellulose papers. The latter, however, contain a large number of cavities that can be filled with atmospheric air and moisture or an impregnating dielectric. Therefore, the permittivity, conductivity and breakdown voltage of insulating materials is a complex function of the presence and placement of certain components in the volume of the dielectric. In this paper, we consider the effect of the composition of an insulating material on its effective permittivity.

Literature review. To calculate the effective permittivity $(\mathrm{EP}) \varepsilon_{\mathrm{eq}}$ of two-component materials, the formulas of Wiener, Rayleigh, Maxwell, generalized Lichtenecker formula for flat, cylindrical, spherical and granular inclusions $[1,2]$, as well as the Odelevsky formula for statistical mixtures can be used:

$$
\begin{gathered}
\left(\varepsilon_{\mathrm{eq}}+k\right)^{-1} V_{\Sigma}=\left(\varepsilon_{1}+k\right)^{-1} V_{1}+\left(\varepsilon_{2}+k\right)^{-1} V_{2} ; \\
\left(\varepsilon_{\mathrm{eq}}-\varepsilon_{1}\right) /\left(\varepsilon_{\mathrm{eq}}+\varepsilon_{2}\right)=\left(\varepsilon_{2}-\varepsilon_{1}\right)\left(\varepsilon_{2}+\varepsilon_{1}\right)^{-1} V_{2} V_{\Sigma}^{-1} ; \\
\varepsilon_{\mathrm{eq}}=\varepsilon_{1}\left[1+\left(3 V_{2}\left(\varepsilon_{2}-\varepsilon_{1}\right) / V_{\Sigma}\right) /\left(\varepsilon_{2}+2 \varepsilon_{1}-V_{2}\left(\varepsilon_{2}-\varepsilon_{1}\right) / V_{\Sigma}\right)\right] ; \\
\varepsilon_{\mathrm{eq}}^{m} V_{\Sigma}=\sum_{j=1}^{n} V_{j} \varepsilon_{j}^{m} ; \\
\varepsilon_{\mathrm{eq}}=A+\sqrt{A^{2}+\varepsilon_{1} \varepsilon_{2} / 2}
\end{gathered}
$$

where $\varepsilon_{1}, \varepsilon_{2}$ are the permittivities of the components of the material; $V_{\Sigma}, V_{1}, V_{2}$ are the total volume and volumes of 
the components of the material, respectively; $k$ is the Wiener coefficient, $0 \leq k \leq \infty$; $n$ is the number of components of the material; $m$ is the Lichtenecker index, $-1 \leq m \leq 1 ; A$ is the Odelevsky parameter

$$
A=\left[\left(3 V_{1} / V_{\Sigma}-1\right) \varepsilon_{1}+\left(3 V_{2} / V_{\Sigma}-1\right) \varepsilon_{2}\right] / 4 \text {. }
$$

The use of formulas (1), (4) is difficult due to the unknown coefficients $k$ and $m$. Formulas (2), (3) and (5) are derived on the basis of certain assumptions, the violation of which can lead to a significant error.

To determine the EP of impregnated paper, in [3] it is proposed to use a model of series-connected layers, which is a rather rough approximation.

In [4-6], using the double and triple-periodic Rayleigh model, effective material parameters are calculated based on the solution of the static field problem by the method of summing multipole interactions. The field models in these works for reducing infinite sums of interactions to their finite sum are limited only by the nearest neighbors with respect to the chosen inclusion.

Calculation of the EP can be based on the polarization mechanism [7]. This approach is mainly applied only for pure substances with consideration of processes at the ionic and molecular levels. In [8], based on field models, the electrophysical properties of a cement-based composite were explained.

Therefore, a sufficiently accurate determination of the averaged characteristics of the material is based on the solution of the corresponding field model of the system of solid substances located in the volume of the material in accordance with the technology of its manufacture.

The goal of the work is the development of a twodimensional numerical-field model for determining the EP of a multicomponent material represented by a system of homogeneous volumes with known physical characteristics.

Object of study. A rectangular parallelepiped made of capacitor paper with the following dimensions: length $l=100 \mu \mathrm{m}$; width $b=200 \mu \mathrm{m}$; height $h=14 \mu \mathrm{m}$ for papers $\mathrm{KOH} 0,8 ; \mathrm{KOH} 2 ; \mathrm{MKOH} 1$ or height $h=12 \mu \mathrm{m}$ for paper $\mathrm{CKOH} \mathrm{3,5.} \mathrm{Humidity,} \mathrm{composition} \mathrm{and} \mathrm{density}$ of the selected paper grades correspond to [9].

Mathematical model. The main physical properties of the materials needed to build mathematical models for determining the EP of a particular paper are given in Table 1. The temperature of the insulating paper is taken $60{ }^{\circ} \mathrm{C}$.

Table 1

Physical properties of dielectric materials

\begin{tabular}{|l|c|c|c|}
\hline \multicolumn{1}{|c|}{ Name } & $\begin{array}{c}\text { Density, } \\
\mathrm{kg} / \mathrm{m}^{3}\end{array}$ & $\varepsilon_{20}$ & $\alpha, 1 /{ }^{\circ} \mathrm{C}$ \\
\hline Cellulose & 1530 & 6.5 & $0.5 \cdot 10^{-3}$ \\
\hline Air & 1,06 & 1.00058 & $-1.5 \cdot 10^{-6}$ \\
\hline Water & 983 & 80.2 & $-4.02 \cdot 10^{-3}$ \\
\hline Transformer oil & 856 & 2.25 & $-0.5 \cdot 10^{-3}$ \\
\hline
\end{tabular}

The permittivity of the material at an arbitrary temperature $t$ is determined as

$$
\varepsilon=\varepsilon_{20}[1+\alpha(t-20)] \text {. }
$$

The veracity of expression (6) is confirmed by the graphical dependencies shown in Fig. 1 for dry air and water, recommendations in [3] for cellulose and the linear dependence of the permittivity of transformer oil on temperature within $20 \ldots 90{ }^{\circ} \mathrm{C}$. The assumption of the absence of thermal aging of the material also applies.
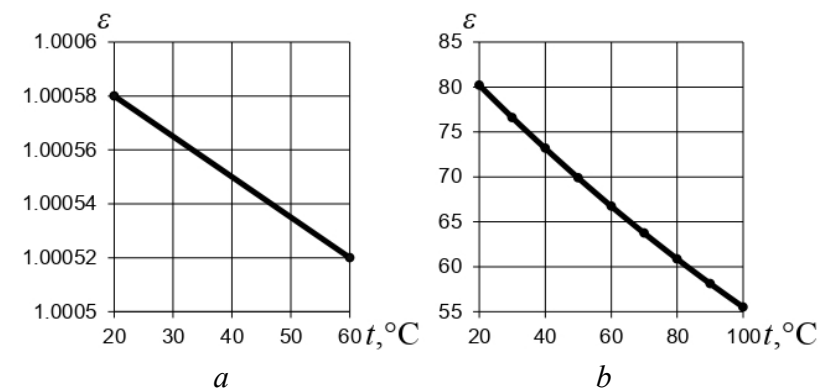

Fig. 1. Dependence of the permittivity of dry air $(a)$ and water $(b)$ on temperature

Real insulating paper is presented as cellulose with cylindrical pores uniformly spaced in its volume. Cross sections of pores are in planes perpendicular to the length of the volume under consideration. Depending on the model formulation, air, air and water, transformer oil may be in the pores.

The volumes of cellulose and pores are found by solving the system of equations:

$$
\left\{\begin{array}{l}
V_{\mathrm{p}} \rho_{\mathrm{p}}(1-y)=V_{\mathrm{c}} \rho_{\mathrm{c}}+V_{\mathrm{a}} \rho_{\mathrm{a}} \\
V_{\mathrm{w}} \rho_{\mathrm{w}}=V_{\mathrm{p}} \rho_{\mathrm{p}} y \\
V_{\mathrm{p}}=V_{\mathrm{c}}+V_{\mathrm{a}}+V_{\mathrm{w}}
\end{array}\right.
$$

where $V_{\mathrm{p}}, V_{\mathrm{c}}, V_{\mathrm{a}}$ and $V_{\mathrm{w}}$ are the volumes of paper, cellulose, air and water, respectively; $\rho_{\mathrm{p}}, \rho_{\mathrm{c}}, \rho_{\mathrm{a}}$ and $\rho_{\mathrm{w}}$ are the densities of paper, cellulose, air and water, respectively; $y$ is the relative mass content of water in the insulating paper [9].

The electric field in cross section relative to the length of the considered volume of insulating paper is described by the following differential equations [10]:

$$
\begin{aligned}
& \varepsilon^{2} \varphi=-\rho ; \\
& \boldsymbol{E}=-\nabla \varphi ; \\
& \boldsymbol{D}=\varepsilon \boldsymbol{E},
\end{aligned}
$$

where $\varphi$ is the scalar electrostatic potential; $\rho$ is the volume charge density of the domain; $\boldsymbol{E}$ is the electric field vector; $\boldsymbol{D}$ is the electric induction vector.

At the interface, the following conditions are satisfied [10]:

$$
\begin{aligned}
& \left\{\begin{array}{l}
\mathbf{n}_{12} \times\left[\nabla \varphi_{1}-\nabla \varphi_{2}\right]=0 ; \\
\mathbf{n}_{12} \cdot\left(\varepsilon_{1} \nabla \varphi_{1}-\varepsilon_{2} \nabla \varphi_{2}\right)=\sigma ;
\end{array}\right. \\
& \left\{\begin{array}{l}
\varphi_{1}=\varphi_{2} ; \\
\varepsilon_{1} \frac{\partial \varphi_{1}}{\partial \mathbf{n}_{12}}-\varepsilon_{2} \frac{\partial \varphi_{2}}{\partial \mathbf{n}_{12}}=\sigma,
\end{array}\right.
\end{aligned}
$$

where $\mathbf{n}_{12}$ is the normal from the first to the second medium; $\sigma$ is the surface charge at the interface between two media.

Equation (7) in a piecewise homogeneous dielectric medium is reduced in each homogeneous region to the Laplace equation, and the permittivities of the regions is included in the solution of the problem only by means of conditions (8). 
The second equation of condition (8) at the interfaces between two dielectrics, as well as a dielectric and a conductor, respectively, takes the form:

$$
\varepsilon_{1} \frac{\partial \varphi_{1}}{\partial \mathbf{n}_{12}}-\varepsilon_{2} \frac{\partial \varphi_{2}}{\partial \mathbf{n}_{12}}=0 ; \varepsilon_{1} \frac{\partial \varphi_{1}}{\partial \mathbf{n}_{12}}=\sigma .
$$

On the upper and lower planes perpendicular to the height of the volume under consideration, Dirichlet conditions respectively $\varphi_{\mathrm{d} 1}=1.9 \mathrm{~V} ; \varphi_{\mathrm{d} 2}=-1.9 \mathrm{~V}$ are set. The solution domain is limited to a cylindrical surface with a radius of $200 \mu \mathrm{m}$, a length of $100 \mu \mathrm{m}$, and zero potential on its surface.

After the numerical calculation of the electric field the energy enclosed in the volume of insulating paper is found

$$
W=\int_{V} \frac{1}{2} \boldsymbol{E} \cdot \boldsymbol{D} d v=\frac{1}{2} \int_{V} \varepsilon(\nabla \varphi)^{2} d v,
$$

where $V$ is the volume over which the integration is performed; $v$ is the elementary volume.

By comparing the calculated energy with the energy of a flat capacitor, we find the EP

$$
\varepsilon_{\mathrm{eq}}=\frac{2 W h}{l b\left(\varphi_{\mathrm{d} 1}-\varphi_{\mathrm{d} 2}\right)^{2}} .
$$

The numerical calculation of the electrostatic field by the finite element method is implemented in the FEMM code.

The main assumptions of the model: dielectric materials do not have conductivity; there are no charges at their interfaces; space charges in dielectric materials are absent, and their volumes do not change under the influence of an electrostatic field; ideal conductors with infinitesimal height are sources of an electrostatic field.

The significant width of the investigated dielectric is explained by the desire to reduce the edge effect. The model was tested by comparing capacitor capacities with sizes $100 \times 200 \times 14 \mu \mathrm{m}$ and the same thickness of cellulose and air obtained on the basis of the equations of the electrostatic field by the finite element method and on the basis of the analytical expression without taking into account the edge effect. The error in this case was $0.23 \%$.

The results of the study. To calculate the EP of dry and transformer oil-soaked insulating papers, we used models of uniformly distributed cylindrical volumes filled with air and transformer oil, respectively, in cellulose matrices.

To calculate the EP of wet paper, a model of uniformly distributed cylindrical volumes filled with air and water was proposed, and in this total volume the volume of water was represented as cylindrical with a circular cross section in a cellulose matrix. When determining the volume content of a particular component, the author was based on the structure of wet paper (that is, paper with normal water content [9]), therefore, the pore volume (the sum of the volume of air and water for wet paper) in the models of dry and impregnated paper did not change. The calculated EPs for the indicated models, as well as for the layered model, Rayleigh and Odelevsky models are given in Table 2 .

\begin{tabular}{|c|c|c|c|c|c|c|c|c|}
\hline \multirow{2}{*}{ Paper grade } & \multicolumn{3}{|c|}{ Proposed model } & \multicolumn{2}{|c|}{ Layer model } & \multirow{2}{*}{$\begin{array}{c}\begin{array}{c}\text { Rayleigh } \\
\text { model }\end{array} \\
\varepsilon_{\mathrm{eq}}\end{array}$} & \multirow{2}{*}{$\begin{array}{c}\text { Odelevsky } \\
\text { model } \\
\\
\varepsilon_{\mathrm{eq}}\end{array}$} & \multirow{2}{*}{$\begin{array}{c}\begin{array}{c}\text { Approximation } \\
\text { dependence }\end{array} \\
\varepsilon_{\mathrm{eq}}\end{array}$} \\
\hline & $\begin{array}{c}\text { Number of } \\
\text { pores }\end{array}$ & $\begin{array}{l}\text { Number of } \\
\text { model nodes }\end{array}$ & $\varepsilon_{\mathrm{eq}}$ & $\begin{array}{c}\text { Number of } \\
\text { model nodes }\end{array}$ & $\varepsilon_{\mathrm{eq}}$ & & & \\
\hline \multicolumn{9}{|c|}{ dry paper } \\
\hline Paper KOH 0,8 & 248 & 662632 & 3.052 & 4607 & 1.682 & 4.500 & 2.860 & 3.052 \\
\hline Paper KOH 2 & 248 & 702562 & 4.370 & 4749 & 2.543 & 5.300 & 4.456 & 4.507 \\
\hline Paper МКОН 1 & 248 & 693639 & 3.674 & 4920 & 2.048 & 4.895 & 3.667 & 3.783 \\
\hline Paper СКОН 3,5 & 248 & 750148 & 4.966 & 4872 & 3.150 & 5.665 & 5.114 & 5.123 \\
\hline \multicolumn{9}{|c|}{ wet paper } \\
\hline Paper КОН 0,8 & 248 & 4462060 & 3.403 & 5566 & 1.912 & - & - & 2.740 \\
\hline Paper KOH 2 & 248 & 4877348 & 5.185 & 5652 & 3.503 & - & - & 5.185 \\
\hline Paper МКОН 1 & 248 & 4744585 & 4.130 & 5509 & 2.448 & - & - & 3.634 \\
\hline Paper СКОН 3,5 & 248 & 3782978 & 6.262 & 6711 & 5.095 & - & - & 6.808 \\
\hline \multicolumn{9}{|c|}{ impregnated paper } \\
\hline Paper КОН 0,8 & 248 & 662632 & 3.949 & 4607 & 3.233 & 4.789 & 3.914 & 3.949 \\
\hline Paper KOH 2 & 248 & 702562 & 5.000 & 4749 & 4.212 & 5.525 & 5.068 & 5.06 \\
\hline Paper MKOH 1 & 248 & 693639 & 4.453 & 4920 & 3.686 & 5.155 & 4.503 & 4.516 \\
\hline Paper CКОН 3,5 & 248 & 750148 & 5.448 & 4872 & 4.755 & 5.835 & 5.540 & 5.525 \\
\hline
\end{tabular}

Table 2

Simulation results

The decrease in the EP values according to the layered model relative to the proposed one is explained by the need for the entire electric flux to pass through the region with low dielectric constant. The Rayleigh model 
also cannot claim to be a good description of the change in the EP when the volumes and properties of the components of the material change and gives overestimated values. The Odelevsky model determines the EP with an accuracy of 2.98...6.3\% and $-1.7 . .0 .9 \%$ for dry and impregnated paper, respectively. On the basis of field models and the generalized Lichtenecker formula, approximation dependences are proposed for calculating the EP of insulating papers. The approximation dependences indexes for dry, wet and transformer oil-soaked papers amounted to $0.495 ;-0.283$ and 0.391 , respectively. The EPs calculated by this method are given in Table 2 .

The effect of the number of inclusions on the EP value of KOH 2 dry paper is shown in Fig. 2, from which it can be seen that with an increase in the number of uniformly distributed volumes of inclusions, the accuracy of the model increases until it begins to be limited by the accuracy of displaying the boundaries of these volumes.

Consequently, the proposed models for the specified in Table 2 numbers of pores accurately enough allow to determine the EP.

In addition to the above wet paper models, models with a cylindrical volume of water and a sector section, as well as with a cylindrical volume of water, in the cavity of which a cylindrical air volume is coaxially located are considered.

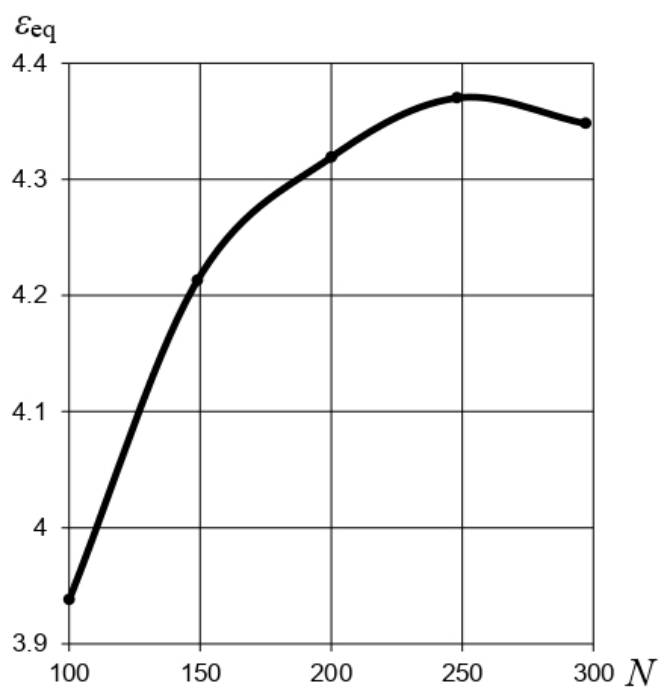

Fig. 2. Dependence of the permittivity on the number of pores of the model of dry paper grade $\mathrm{KOH} 2$

The maximum discrepancy between the EPs calculated for models with a circular and sector section of the water volume was $2.9 \%$, therefore, these models are equivalent. Examples of the distribution of the electrostatic field in these models are shown in Fig. 3, 4.

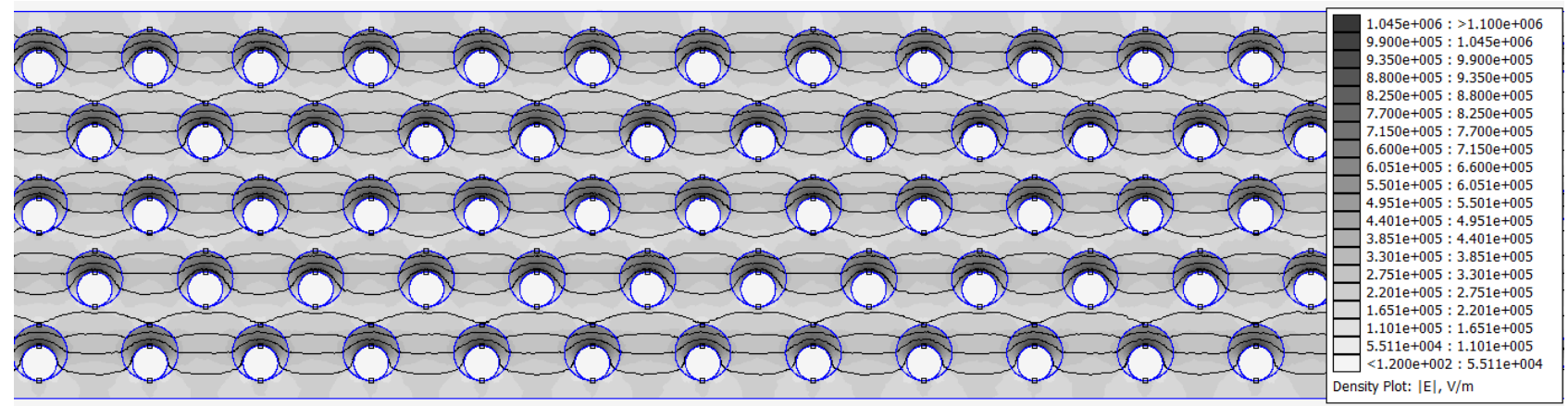

Fig. 3. Distribution of the electrostatic field in the model of wet paper brand $\mathrm{KOH} 2$ with a circular cross section of the volume of water

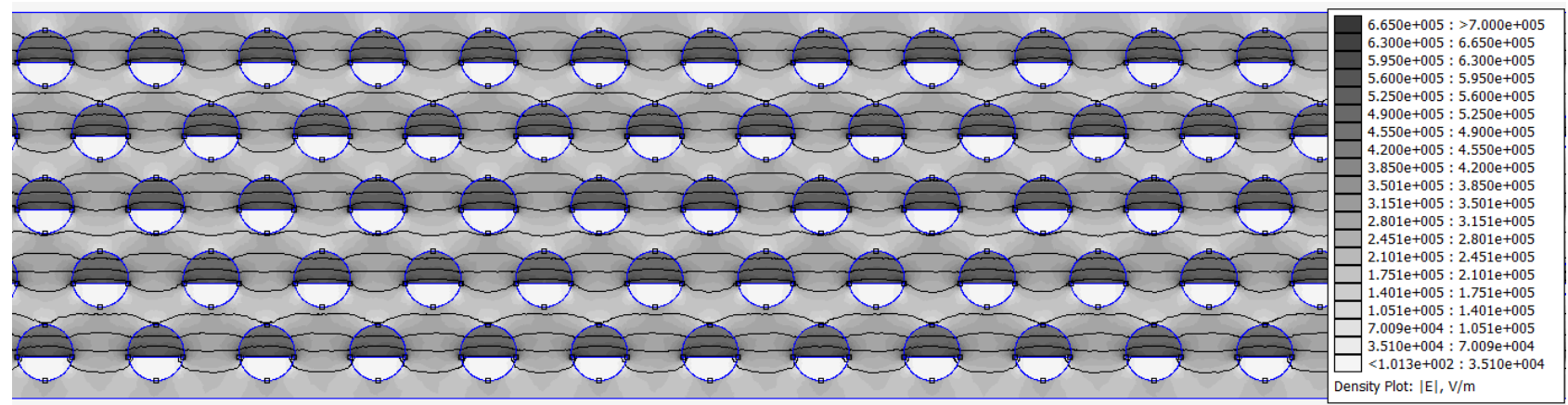

Fig. 4. Distribution of the electrostatic field in the model of wet paper brand $\mathrm{KOH} 2$ with a sector cross-section of the volume of water

As can be seen from Fig. 3, 4, with almost identical EPs, the electric field strength modulus in the air in the first model is greater than in the second one. The EP values determined for models with a hollow cylindrical volume of water are 1.36...1.8 times greater than for a model with a cylindrical volume of circular cross section, which is explained by the formation of a path with an increased permittivity. This model was discarded due to the presence of a local extremum of the EP value when changing paper grades.

For the KOH 2 dry paper model and pore number 100 , the effect of the location of pores at the nodes of a rectangular and parallelogram mesh on the final result was studied. The maximum discrepancy was $0.8 \%$.

It is known that $\mathrm{CKOH}$ paper is characterized by a significant, up to $1 \%$, ash content. In the manufacture of 
paper calcium sulfate can be considered as ash. The calculated values of the EP of $\mathrm{CKOH}$ insulating paper, taking into account ash, are given in Table 3. The error of not accounting of ash was $0.8 \ldots 1.3 \%$.

СКОН 3,5 paper simulation results

Table 3 with ash inclusions $1 \%$

\begin{tabular}{|l|c|c|c|c|}
\hline Paper type & $\begin{array}{c}\text { Number of } \\
\text { pores }\end{array}$ & $\begin{array}{c}\text { Number of } \\
\text { inclusions of } \\
\text { ash }\end{array}$ & $\begin{array}{c}\text { Number of } \\
\text { model nodes }\end{array}$ & $\varepsilon_{\mathrm{eq}}$ \\
\hline Dry & 248 & 49 & 843735 & 4.925 \\
\hline Wet & 248 & 49 & 3997067 & 6.182 \\
\hline Impregnated & 248 & 49 & 843735 & 5.415 \\
\hline
\end{tabular}

Conclusions.

1. The principal possibility of describing the permittivity of a mixture of components on the basis of field models with the known permittivity of each component, their volumetric content and the features of their location is shown. Field models have been developed for determining the EP of dry, wet, and transformer oil-soaked insulating papers.

2. The adequacy of the developed models is confirmed by the following: with an increase in the number of cylindrical volumes inside the matrix, the EP asymptotically tends to a certain finite value.

3. The layered model and the Rayleigh model give, respectively, underestimated and overestimated values of the EP relative to the proposed field model. These alternative models suitably describe only a mixture of components with close permittivities.

4. Approximate dependencies of the behavior of the EP of component mixtures with a change in their volume content, constructed on the basis of the generalized Lichtenecker model and the proposed field models, have comparable accuracy with the Odelevsky model for twocomponent materials and a 2 -fold reduced error relative to the layered model for three-component materials.

5. Models with the arrangement of cylindrical volumes in the nodes of a rectangular and parallelogram mesh give the same result when calculating the EP of a macroscopically homogeneous heterogeneous material.

\section{REFERENCES}

1. Raju G. G. Dielectrics in electric fields. New York, Marcel Dekker, 2003. 578 p.

2. Moulson A.J., Herbert J.M. Electroceramics: materials, properties, applications. Chichester, John Wiley \& Sons Ltd, 2006. $557 \mathrm{p}$.

3. Shcheglov N.V. Sovremennye vidy izoliatsii. Izoliatsiia silovykh kondensatorov [Modern types of isolation. Power capacitor isolation]. Novosibirsk, NSTU Publ., 2016. 116 p. (Rus).

4. Balagurov B.Ya., Kashin V.A. Electrophysical properties of the Rayleigh three-dimensional model. Technical Physics, 2007, vol. 52, no. 2, pp. 216-225. doi: 10.1134/s1063784207020119.

5. Emets Yu.P. Electrical characteristics of three-component dielectric composites with close-packed inclusions. Journal of Applied Mechanics and Technical Physics, 2001, vol. 42, iss. 4, pp. 704-713. doi: 10.1023/A:1019272201997.

6. Tolmachev S.T., Yukhymovych D.L. The problem of reducing the hollow circular cylinders with arbitrary grating of periods for regular system. Technical Electrodynamics, 2011, no. 2, pp. 11-17. (Rus).

7. He T. Effects of impurities on silicon dioxide dielectric properties. Advanced Materials Research, 2014, vol. 1022, pp. 56-59. doi: 10.4028/www.scientific.net/AMR.1022.56.

8. Chen R.J., Zhang Y., Wang B. Numerical simulation study on the cement-based absorbing material. Advanced Materials Research, 2013, vol. 853, pp. 169-173. doi: 10.4028/www.scientific.net/AMR.853.169.

9. DSTU 3467-96. Papir kondensatornyj. Zagal'ni tehnichni umovy. [DSTU 3467-96. State standard of Ukraine. Capacitor paper. General technical conditions]. Kyiv, Derzhstandart of Ukraine Publ., 1996. 34 p. (Ukr).

10. Stratton J.A. Electromagnetic theory. Hoboken, IEEE Press, 2007. $630 \mathrm{p}$.

Received 17.01.2020

O.O. Palchykov, Candidate of Technical Science, Associate Professor,

Admiral Makarov National University of Shipbuilding,

9, Heroyiv Ukraine Ave, Mykolaiv, Ukraine, 54025, тел/phone +380958934509;

e-mail: ole2012hulk@gmail.com

\section{How to cite this article:}

Palchykov O.O. Determination of the effective permittivity of a heterogeneous material. Electrical engineering \& electromechanics, 2020, no.2, pp. 59-63. doi: 10.20998/2074-272X.2020.2.09. 